\title{
Valuations of SF-6D health states: Could United Kingdom data be used to select a smaller sample of Hong Kong states
}

\author{
Samer A Kharroubi* \\ Department of Nutrition and Food Sciences, Faculty of Agricultural and Food Sciences, American University of Beirut, Beirut, \\ Lebanon
}

Received: April 18, 2016

Accepted: June 15, 2016

Online Published: October 25, 2016

DOI: $10.5430 / \mathrm{ijh} . v 3 \mathrm{n} 1 \mathrm{p} 1$

URL: http://dx.doi.org/10.5430/ijh.v3n1p1

\begin{abstract}
Background: There is interest in the extent of using the combined analysis when we have plenty of data on two countries, but few have considered the combined analysis when we have plenty of data on one country and limited data on another. This kind of analysis may produce better estimation of the second country's population utility function than analysing its data separately.

Methods: The data set is the HK and UK SF-6D valuation studies where two samples of 197 and 249 states defined by the SF-6D were valued by representative samples of the HK and UK general populations respectively, both using the standard gamble technique. We apply a nonparameteric Bayesian method to estimate a utility function applicable across both countries to see whether with a small sample of HK health states, but also drawing extra information from the UK data, we obtain the same accuracy we would get with the full HK sample.

Results: The results suggest that with the use of 100 health states, the HK analysis gets the broad features as the full analysis with all states as far as predicted mean valuations, covariates, interactions, regression parameters and dimension-specific parameters are concerned.

Conclusions: The implications of these results will be hugely important in countries without the same capacity to run large evaluation exercises.
\end{abstract}

Key Words: Preference-based health measure, Nonparametric methods, Standard gamble, SF-6D

\section{INTRODUCTION}

There has been an increasing use of preference-based measures of health related quality of life in order to calculate quality adjusted life years (QALYs) for use in cost effectiveness analyses. These preference-based measures are standardised multi-dimensional health state classifications with preference or utility weights elicited from a sample of the general population. ${ }^{[1]}$ There are currently a number of such preference-based measures, including generic measures such as EQ-5D, ${ }^{[2]}$ HUI2 \& $3,{ }^{[3,4]}$ AQoL, ${ }^{[5]}$ and the SF-6D ${ }^{[6]}$ and condition specific measures. ${ }^{[7-10]}$ These measures provide empirically derived health state values that can be used to derive QALYs for use in a cost-effectiveness analysis or cost-utility analysis. ${ }^{[11]}$

The SF-6D has become a widely used measure of health status and it has been valued in 5 other countries to date. ${ }^{[12-16]}$

\footnotetext{
* Correspondence: Samer A Kharroubi, PhD; Email: sk157@aub.edu.lb; Address: Department of Nutrition and Food Sciences, Faculty of Agricultural and Food Sciences, American University of Beirut, Beirut, Lebanon. 
There is a concern that people in different countries and cultures may value health differently, and so may give different utilities for the same health state descriptions. Such differences will mean that valuations derived in one country cannot be used to give valid cost-effectiveness analyses in another. Earlier research with the EQ-5D found quite small and largely unimportant differences between UK, US and Spain. ${ }^{[17]}$ Data sets using one of the choice-based techniques such as standard gamble (SG) or time trade-off have found important differences between the USA and UK, ${ }^{[18]}$ Japan and UK, ${ }^{[19]}$ and between Portugal and the UK. ${ }^{[20]}$

Kharroubi et al. ${ }^{[21]}$ extended this work by using a new nonparametric Bayesian method to model the differences between these countries that is simpler, better fitting and more appropriate for the data than the conventional parametric methods on the US vs. UK comparison for EQ-5D. ${ }^{[18]} \mathrm{Khar}-$ roubi et al. ${ }^{[22,23]}$ have also applied it to the SF-6D HK and UK and Japan and UK valuation data. There are two distinct ways in which such a model for estimating population utility functions for each country may be useful. When we have plenty of data on two countries, good estimates of population utility functions for each country can be obtained by analysing the data from each country separately (using the model of Ref. ${ }^{[24]}$ ).

However, when we have plenty of data on one country and limited data on another, we believe the combined analysis may produce better estimation of the second country's population utility function than analysing its data separately. This kind of analysis (borrowing strength from country 1) may allow us to reduce sample sizes in country 2 in order to obtain the same accuracy as we would get with a full-sized study in that country. This will be hugely important in countries without the same capacity to run large evaluation exercises.

Our primary purpose in this article is to demonstrate a powerful approach to see whether with a small sample of HK health states, but also drawing extra information from the UK data, we get results that are as good as those obtained with the full HK sample. To our knowledge, this is something that hasn't been explored properly yet, but is obviously of potential value.

Section 2 of this article provides a brief description of the HK and UK SF-6D valuation surveys and the data used in this article. Section 3 sets out a Bayesian nonparametric model that provides more realistic and flexible inferences for preference functions. Section 4 presents the results of using the Bayesian method to demonstrate the potential for reducing sample sizes using the HK and UK SF-6D data sets. Finally, we conclude with a general discussion of the results in Section 5, including few directions for future research.

\section{MethodS}

\subsection{SF-6D data set}

The SF-6D, derived from the SF-36, has been described elsewhere. ${ }^{[6,25]}$ It has six dimensions of physical functioning, role limitation, social functioning, bodily pain, mental health and vitality, each with between four and six levels. ${ }^{[6]}$ An SF-6D health state is defined by selecting one statement from each dimension, starting with physical functioning and ending with vitality. Level 1 in each dimension represents no loss of health or functioning in that dimension, so that state 111111 denotes perfect health. The worst possible state is 645655 , known as "the pits". A total of 18,000 health states can be defined in this way.

\subsubsection{UK}

A selection of 249 states defined by the SF-6D have been valued by a representative sample of 836 members of the UK general population using the standard gamble (SG) valuation technique. The selection of respondents and the selection of health states are discussed elsewhere. ${ }^{[6]}$ Each respondent was asked to rank and then value six SF-6D health states using the McMaster "ping pong" variant of SG, where respondents are iterated towards their point of indifference. ${ }^{[26]}$ The SG valuation task asked respondents to value each of five SF-6D health states against perfect health and "pits". Respondents were then asked in the sixth SG question to value "pits". See Ref. ${ }^{[6]}$ for more details.

Of the original 836 respondents, 225 were excluded for a number of reasons, the most important being that $130 \mathrm{did}$ not provide a value for the "pits" state and so their data could not be used. Out of the remaining 611 individuals included in the data set there were 148 missing values from 117 individuals. This results in 3,518 $(6 \times 611-148)$ observed SG valuations across 249 health states. The details of the valuations for each of the 249 SF-6D UK health states are in Ref. ${ }^{[6]}$

\subsubsection{Hong Kong}

The HK study used a sample of 197 health states and valued them using the same valuation methods as in the UK study. ${ }^{[15]}$ The selection of respondents and the selection of health states follow the same UK procedures. Each respondent was asked to rank and value eight health states. As in Ref., ${ }^{[6]}$ the states were stratified into a block system in order to ensure each person valued a range of health states from very mild to very severe. The interview procedure was modelled on that used in the UK study.

Of the original 641 respondents, 59 were excluded from the analysis using the same exclusion criteria as in the UK study. ${ }^{[6]}$ Out of the remaining 582 individuals included in the data set there were 60 missing health state values. This results in 4,596 $(8 \times 582-60)$ observed SG valuations across 
197 health states. The details of the valuations for each of the 197 SF-6D HK health states are in Ref. ${ }^{[15]}$

For combined analysis, we pool the HK and UK data into a single dataset with $m=1,193(611+582)$ respondents. For $j$ $=1,2, \ldots, m$ let $n_{j}$ be the number of health states that were valued by the $j$ th respondent. The total number of observations is $n=\sum n_{j}$. Note that $n=8,114(3,518+4,596)$ for full $\mathrm{HK} / \mathrm{UK}$ dataset. For $i=1,2, \ldots, n_{j}$ and $j=1,2, \ldots, m$, let $\mathbf{x}_{i j}$ be the $i$ th health state valued by respondent $j$, and let $y_{i j}$ be the SG valuation given by respondent $j$ for that health state. Finally, let $\mathbf{t}_{j}$ be a vector of covariates representing individual characteristics of respondent $j$.

\subsection{Modelling}

Kharroubi et al. ${ }^{[21]}$ proposed a nonparametric Bayesian approach to handle a pooled US-UK EQ-5D dataset. This method to modelling has been applied to the HK-UK SF-6D valuation data $^{[22]}$ and to Japan and UK valuation data. ${ }^{[23]}$ Here we follow on from the work of Kharroubi et al. ${ }^{[22]}$ to estimate a utility function to see whether with range of sample sizes of HK health states $(25,50$ or 100 states), but also drawing extra information from the UK data, gets the same broad features as the full HK sample.

The $i$ th valuation by respondent $j$ is modelled as:

$$
y_{i j}=1-\exp \left(\gamma^{\prime} h\left(\mathbf{t}_{j}+\alpha_{j}\right)+\left\{1-u_{c}\left(\mathbf{x}_{i j}\right)\right\}+\varepsilon_{i j}\right.
$$

where $h\left(\mathbf{t}_{j}\right)$ is a vector of functions of the covariates $\mathbf{t}_{j}$ and $\gamma$ is a vector of parameters that together determine the principal effect of the covariates on respondents' valuations, $\alpha_{j}$ is a zero-mean random respondent effect, $\varepsilon_{i j}$ is a zero-mean random error, $u_{c}(\mathbf{x})$ is a function of the health state vector $\mathbf{x}$ and the subscript $c$ represents the respondent's country. As discussed in Kharroubi, ${ }^{[22]} u_{c}(\mathbf{x})$ is interpreted as a base utility function in the sense that if the population expectation of $\exp \left(\gamma^{\prime} h\left(\mathbf{t}_{j}+\alpha_{j}\right)\right.$ is 1 then $u_{c}(\mathbf{x})$ is the population utility measure, where $c=1$ if respondent $j$ is in the HK sample, and $c=0$ if he/she is in the UK sample.

Kharroubi et al. ${ }^{[22]}$ assigned independent normal distributions to the respondents residual and error terms,

$$
\alpha_{j} \sim N\left(0, \tau^{2}\right) \text { and } \varepsilon_{i j} \sim N\left(0, v^{2}\right)
$$

Further, Kharroubi et al. ${ }^{[22]}$ model the relationship between the two base utility functions through

$$
u_{0}(\mathbf{x})=\mu_{0}+\beta_{0}^{\prime} \mathbf{x}+d(\mathbf{x})
$$

$$
u_{1}(\mathbf{x})=\left(\mu_{0}+\mu_{1}\right)+\left(\beta_{0}^{\prime}+\beta_{1}^{\prime}\right) \mathbf{x}+d(\mathbf{x})
$$

where $u_{0}(\mathbf{x}), u_{1}(\mathbf{x}), \beta_{0}$ and $\beta_{1}$ are unknown parameters and $\mathrm{d}(\mathbf{x})$ represents a deviation from the simple linear trend. As in Kharroubi et al., ${ }^{[2]}$ the expression $\mu_{0}+\beta_{0}^{\prime} \mathbf{x}$ in (2) expresses a belief that the underlying utility function $u_{0}(\mathbf{x})$ for UK respondents will tend to behave like a simple linear combination of the elements of the health state description vector $\mathbf{x}$. The coefficients $\beta_{0}$ represent rates at which utility generally declines when we increase the level in the corresponding dimension of $\mathbf{x}$. The comparable expression in (3) modifies these underlying trend variables with additional coefficients $\beta_{1}$ to reflect dimension-specific differences between the HK and UK, but notice they share the same $d(\mathbf{x})$ function.

Finally we let conventional noninformative prior distributions for $\mu_{0}, \mu_{1}, \beta_{0}, \beta_{1}, \tau^{2}$ and $v^{2}$. However,

$$
\mathrm{d}(\mathbf{x}) \sim N\left(0, \sigma^{2}\right)
$$

for all $\mathbf{x}$ and

$$
\operatorname{cov}\left(d(\mathbf{x}), d\left(\mathbf{x}^{\prime}\right)\right)=\exp \left\{-\sum B\left(x_{d}-x_{d}^{\prime}\right)^{2}\right\}
$$

See Kharroubi et al. ${ }^{[24]}$ for more justification of this part of the model. Note that the population utility function in country $c$ is

$$
\bar{u}_{c}(x)=1-\bar{\alpha}_{c}\left\{1-u_{c}(\mathbf{x})\right\}
$$

where $\bar{\alpha}_{c}$ is the population mean/median respondent effect for that country and $u_{c}(\mathbf{x})$ is the corresponding base utility function. The fact that in general $\bar{\alpha}_{c} \neq 1$ and the population utility is not the base utility influences how we interpret the utility slope parameters $\beta_{0}$ for the UK and $\left(\beta_{0}+\beta_{1}\right)$ for the HK. The change in utility for an increase of one level in a particular dimension is represented (as an underlying trend) not by the corresponding slope parameter but by this parameter multiplied by $\bar{\alpha}_{c}$. For this analysis $h(\mathbf{t})$ is set to be (HK, Sex, Age, Age2) where HK is a dummy variable to differentiate respondents' national identity ( 1 if $\mathrm{HK}$ respondent; 0 if $\mathrm{UK}$ respondent) and $A g e^{2}$ is squared age.

\section{RESUlts}

\subsection{HK health states}

We start our analysis by looking at $25 \mathrm{HK}$ health states together with the $249 \mathrm{UK}$ health states. The sample of $25 \mathrm{HK}$ health states was chosen as follows: we first sort HK health 
state in terms of UK mean utilities and then divide them into 25 groups. One health state was then selected at random from each of the 25 groups. Care was taken in selecting the HK sample to ensure it is reasonably well balanced in terms of having high and low levels on each of the 6 dimensions.

Table 1 shows the observed sample mean health state utility and the posterior mean and standard deviation for population mean utility of the 25 health states valued in the HK and UK data (to be referred as HK/UK from now on) and in the HK data on its own (to be referred as HK only from now on). The predicted mean valuations for these states ranged from
0.0196 (pits) to 1 (perfect) for the (HK/UK) population and from 0.0544 (pits) to 1 (perfect) for the (HK only) population. Figure 1 presents the predicted mean health state valuations (green line) for the (HK/UK) along with the predicted mean health state valuations (red line) for the (HK only) and the observed sample mean health state utility of the 25 health states (blue line). The purple line represents the difference between the two predicted (HK/UK) and (HK only) valuations. As can be seen from Figure 1, although both valuations are very similar for the majority of the health states, the two valuations are underestimating the observed ones.

Table 1. Posterior estimates for the 25 sampled health states

\begin{tabular}{|c|c|c|c|c|c|c|}
\hline \multirow[b]{2}{*}{$\begin{array}{l}\text { Health } \\
\text { States }\end{array}$} & \multirow[b]{2}{*}{$\begin{array}{l}\text { Observed } \\
\text { mean }\end{array}$} & \multicolumn{2}{|c|}{ HK data ONLY } & \multicolumn{2}{|c|}{25 HK \& UK data } & \multirow[b]{2}{*}{ Difference } \\
\hline & & $\begin{array}{l}\text { Predicted } \\
\text { mean }\end{array}$ & $\begin{array}{l}\text { Predicted } \\
\text { STD }\end{array}$ & $\begin{array}{l}\text { Predicted } \\
\text { mean }\end{array}$ & $\begin{array}{l}\text { Predicted } \\
\text { STD }\end{array}$ & \\
\hline 111111 & 1 & 1 & 0 & 1 & 0 & 0 \\
\hline 115211 & 0.7951 & 0.7632 & 0.0334 & 0.7788 & 0.0493 & -0.0156 \\
\hline 135312 & 0.7 & 0.6648 & 0.0281 & 0.6786 & 0.0441 & -0.0138 \\
\hline 244353 & 0.6976 & 0.5668 & 0.0322 & 0.5761 & 0.0613 & -0.0093 \\
\hline 434211 & 0.6601 & 0.6238 & 0.0315 & 0.668 & 0.0504 & -0.0442 \\
\hline 435335 & 0.6579 & 0.5733 & 0.0304 & 0.5485 & 0.0634 & 0.0248 \\
\hline 135435 & 0.655 & 0.6004 & 0.0303 & 0.6016 & 0.0558 & -0.0012 \\
\hline 432621 & 0.6423 & 0.5545 & 0.0307 & 0.5432 & 0.0569 & 0.0113 \\
\hline 343425 & 0.6307 & 0.578 & 0.0297 & 0.5543 & 0.0566 & 0.0237 \\
\hline 641114 & 0.6165 & 0.582 & 0.0319 & 0.5716 & 0.057 & 0.0104 \\
\hline 145621 & 0.6093 & 0.5814 & 0.0328 & 0.6214 & 0.0511 & -0.04 \\
\hline 341251 & 0.6023 & 0.5882 & 0.0321 & 0.5504 & 0.0609 & 0.0378 \\
\hline 611621 & 0.5816 & 0.5301 & 0.0324 & 0.4899 & 0.0635 & 0.0402 \\
\hline 145645 & 0.5814 & 0.5158 & 0.0334 & 0.5319 & 0.0613 & -0.0161 \\
\hline 443215 & 0.5719 & 0.5798 & 0.0276 & 0.5528 & 0.0512 & 0.027 \\
\hline 641154 & 0.545 & 0.4952 & 0.0344 & 0.4604 & 0.0694 & 0.0348 \\
\hline 445641 & 0.5364 & 0.4497 & 0.0345 & 0.4472 & 0.0671 & 0.0025 \\
\hline 145652 & 0.5291 & 0.4513 & 0.0359 & 0.4593 & 0.064 & -0.008 \\
\hline 642453 & 0.5104 & 0.4143 & 0.0341 & 0.4093 & 0.0692 & 0.005 \\
\hline 545353 & 0.5103 & 0.4024 & 0.0341 & 0.3829 & 0.0711 & 0.0195 \\
\hline 633122 & 0.4986 & 0.4906 & 0.0291 & 0.4623 & 0.053 & 0.0283 \\
\hline 615614 & 0.4344 & 0.4654 & 0.0329 & 0.4935 & 0.0598 & -0.0281 \\
\hline 644631 & 0.416 & 0.4152 & 0.0328 & 0.3849 & 0.0681 & 0.0303 \\
\hline 645441 & 0.4085 & 0.4032 & 0.0323 & 0.3623 & 0.0655 & 0.0409 \\
\hline 613625 & 0.3453 & 0.4022 & 0.0311 & 0.3308 & 0.0667 & 0.0714 \\
\hline 645655 & 0.067 & 0.0544 & 0.0232 & 0.0196 & 0.0715 & 0.0348 \\
\hline
\end{tabular}

Figure 2 shows the posterior distributions of the covariates (HK, Sex, Age and $\mathrm{Age}^{2}$ ) for the (HK/UK) population. As can be seen, these distributions are concentrated away from zero which indicates that these covariates have important effects. In comparison with Figure 3, the sex effect is of opposite sign and about the same magnitude as the main effect for the (HK only) population. Figure 4 and Figure
5 show the mean SG utility values for the pits state for the (HK/UK) and (HK only) populations respectively. As can be seen, both valuations are very similar.

Figure 6 and Figure 7 show the posterior distributions of the underlying regression parameters $\mu_{0}$ and $\beta_{1}$ of the (HK/UK) and (HK only) respectively. The first distribution is the coefficient of the constant term $\mu_{0}$, but the other 6 elements 
represent slopes of $\beta_{1}$ as each of the 6 dimensions (physical functioning, role limitation, social functioning, bodily pain, mental health and vitality) increases. As can be seen, all of the 6 coefficients in Figure 7 are negative, so the fitted parametric relationship for the $\mathrm{HK}$ only satisfies monotonicity. Whereas in Figure 6, there does seem to be interplay in the $\beta_{1}$ parameters. For dimensions 2 and 3 , the coefficients are concentrated around zero. This may suggest that a sample of $25 \mathrm{HK}$ health state is small and so more HK health states are then needed to obtain results that are as good as those obtained with the full HK sample.

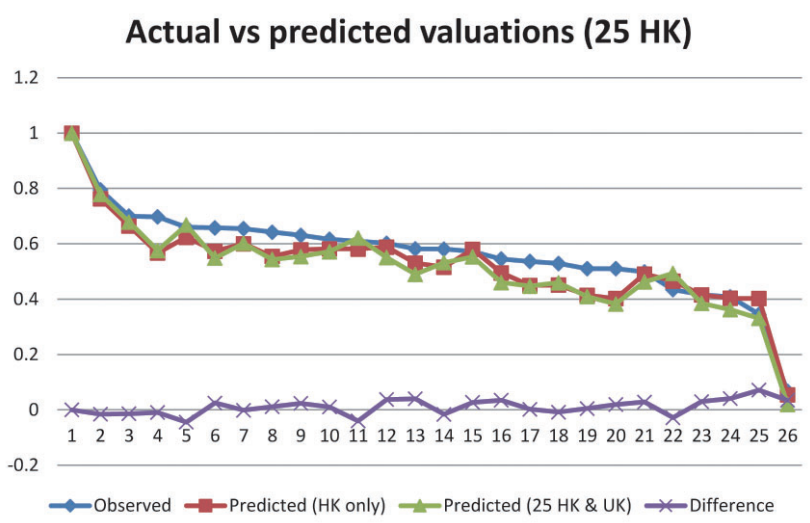

Figure 1. Actual and predicted mean health state valuations for the 25 sampled health states
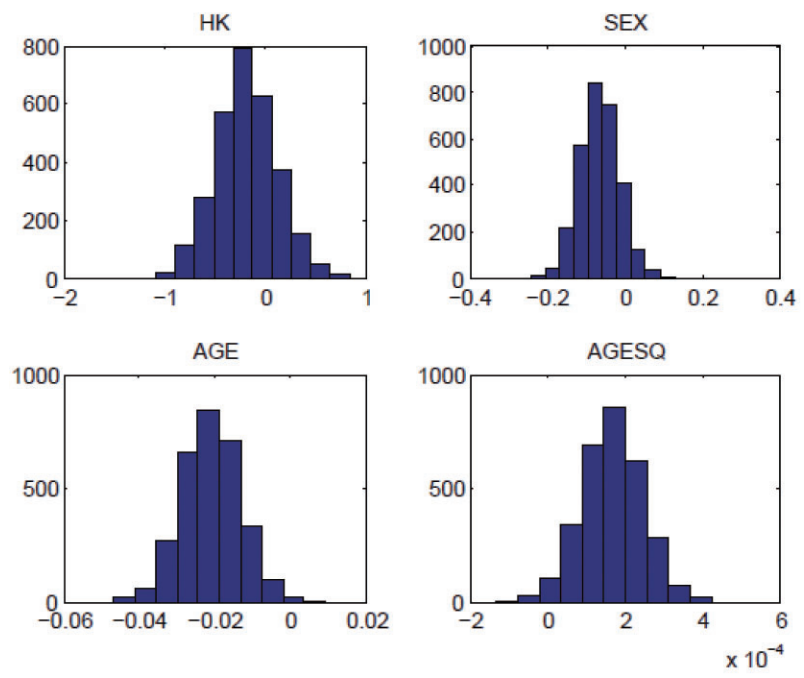

Figure 2. Posterior distribution of the covariates (HK/UK)

\subsection{HK health states}

We continue our analysis by looking at $50 \mathrm{HK}$ health states together with the UK health states. The way of sampling the $50 \mathrm{HK}$ health states is similar to the one mentioned in Section 3.1.
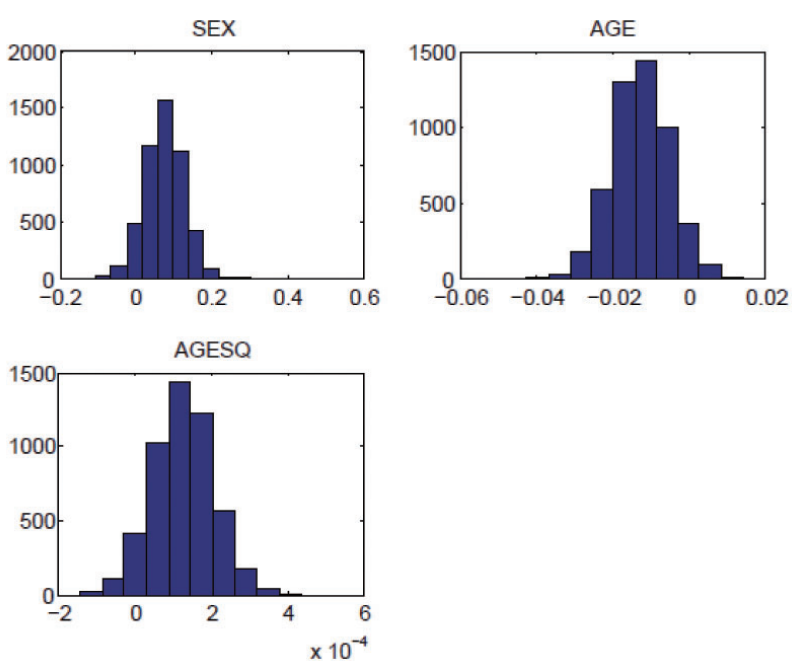

Figure 3. Posterior distribution of the covariates (HK separate fit)

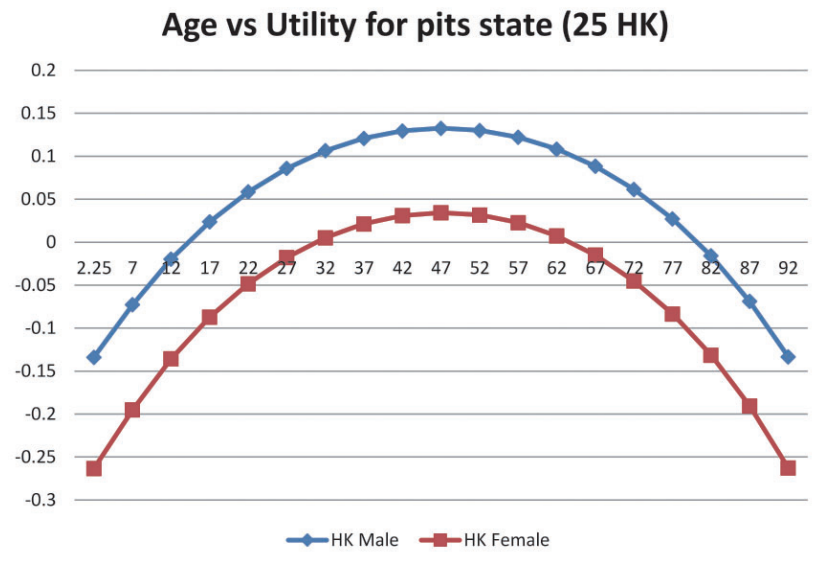

Figure 4. Mean SG utility values by age for pits state: HK/UK

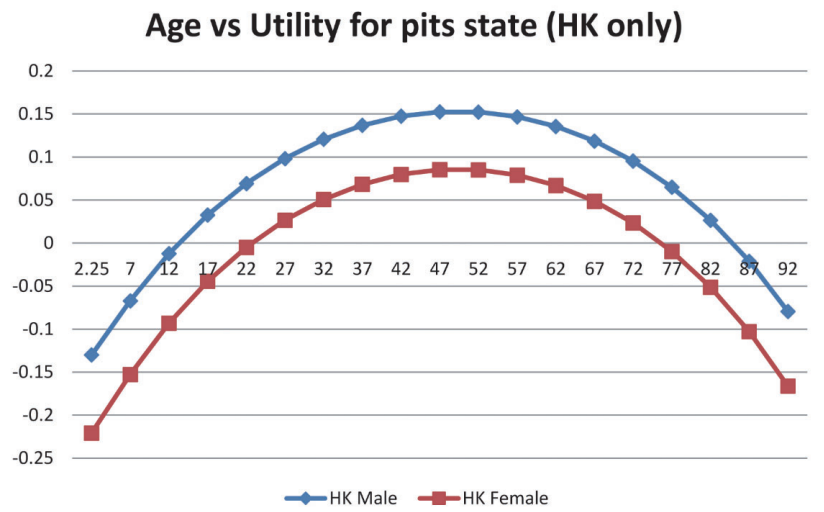

Figure 5. Mean SG utility values by age for pits state: HK only 

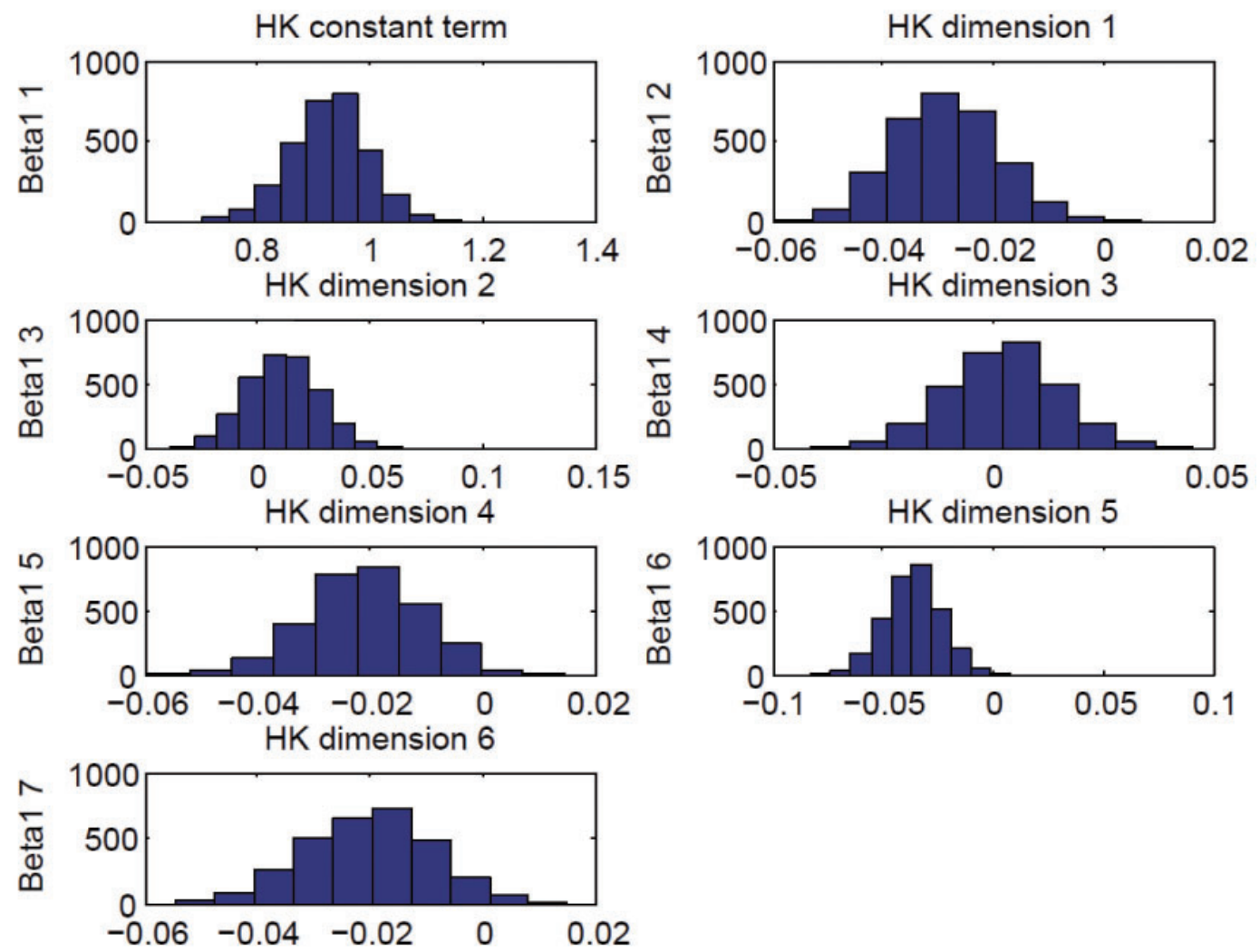

Figure 6. Posterior distribution of the regression parameters $\gamma$ and $\beta$ (HK/UK)
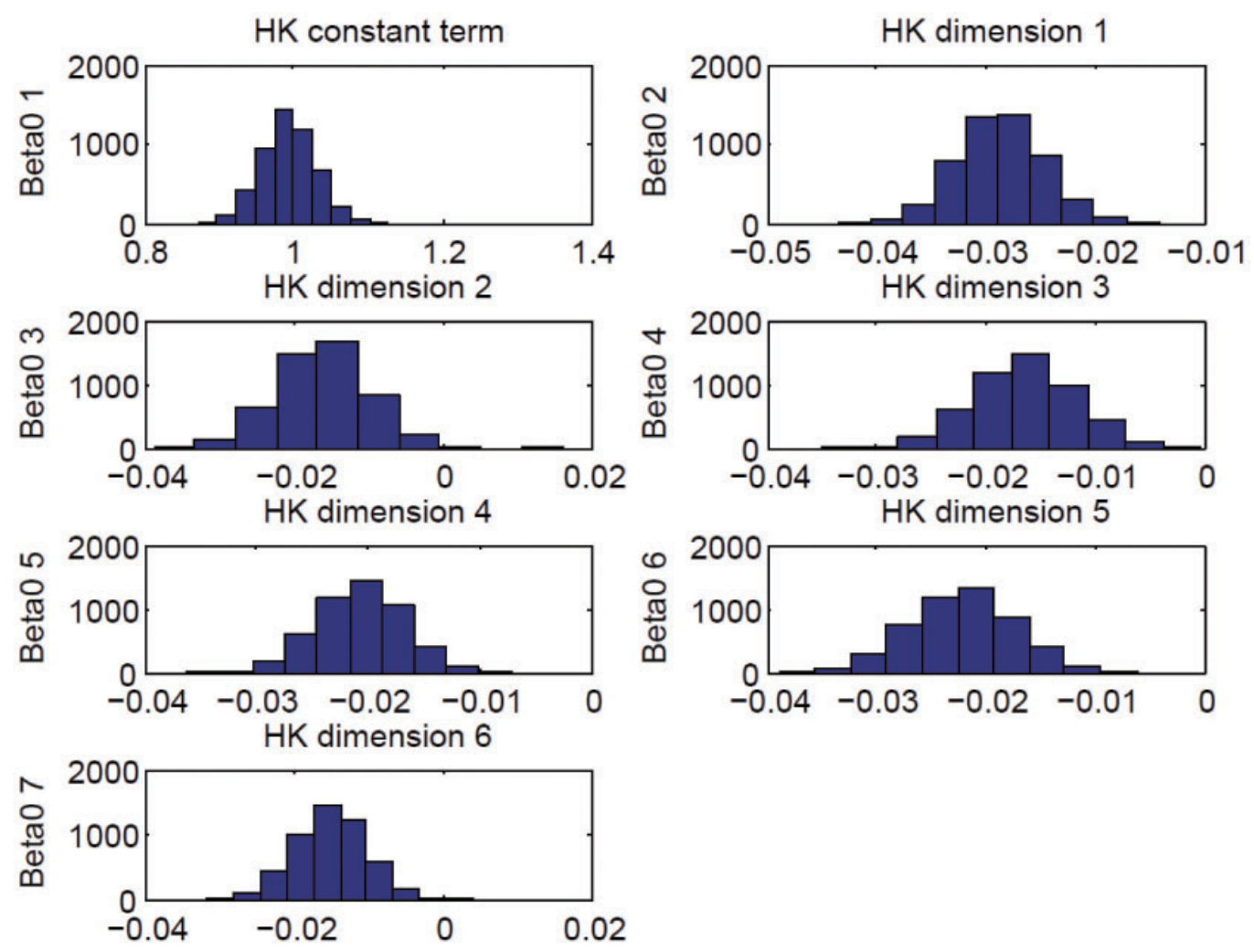

Figure 7. Posterior distributions of the corresponding $\gamma$ and $\beta$ (HK only) 
Table 2. Posterior estimates for the 50 sampled health states

\begin{tabular}{|c|c|c|c|c|c|c|}
\hline \multirow{2}{*}{ Health States } & \multirow{2}{*}{ Observed mean } & \multicolumn{2}{|c|}{ HK data ONLY } & \multicolumn{2}{|c|}{50 HK \& UK data } & \multirow{2}{*}{ Difference } \\
\hline & & Predicted mean & Predicted STD & Predicted mean & Predicted STD & \\
\hline 111111 & 1 & 1 & 0 & 1 & 0 & 0 \\
\hline 115211 & 0.7951 & 0.7632 & 0.0334 & 0.7656 & 0.0426 & -0.0024 \\
\hline 115131 & 0.7243 & 0.7068 & 0.0309 & 0.7225 & 0.0451 & -0.0157 \\
\hline 522321 & 0.7164 & 0.6689 & 0.0272 & 0.6193 & 0.0343 & 0.0496 \\
\hline 141215 & 0.7089 & 0.6765 & 0.032 & 0.6579 & 0.048 & 0.0186 \\
\hline 414522 & 0.7007 & 0.6081 & 0.0314 & 0.5398 & 0.0388 & 0.0683 \\
\hline 135312 & 0.7 & 0.6648 & 0.0281 & 0.6528 & 0.0385 & 0.012 \\
\hline 244353 & 0.6976 & 0.5668 & 0.0322 & 0.5411 & 0.0479 & 0.0257 \\
\hline 122233 & 0.6894 & 0.6726 & 0.0286 & 0.6227 & 0.0347 & 0.0499 \\
\hline 113615 & 0.6685 & 0.6125 & 0.0346 & 0.5601 & 0.0538 & 0.0524 \\
\hline 434211 & 0.6601 & 0.6238 & 0.0315 & 0.6435 & 0.0436 & -0.0197 \\
\hline 435335 & 0.6579 & 0.5733 & 0.0304 & 0.5281 & 0.0469 & 0.0452 \\
\hline 135435 & 0.655 & 0.6004 & 0.0303 & 0.5911 & 0.0459 & 0.0093 \\
\hline 111621 & 0.6492 & 0.6136 & 0.0316 & 0.6023 & 0.0373 & 0.0113 \\
\hline 432621 & 0.6423 & 0.5545 & 0.0307 & 0.5363 & 0.0444 & 0.0182 \\
\hline 345411 & 0.6347 & 0.6118 & 0.0315 & 0.565 & 0.045 & 0.0468 \\
\hline 343425 & 0.6307 & 0.578 & 0.0297 & 0.5334 & 0.0448 & 0.0446 \\
\hline 324155 & 0.6248 & 0.5301 & 0.0349 & 0.4494 & 0.0518 & 0.0807 \\
\hline 211615 & 0.6206 & 0.6275 & 0.0333 & 0.5961 & 0.0465 & 0.0314 \\
\hline 631333 & 0.6175 & 0.521 & 0.0329 & 0.4871 & 0.0467 & 0.0339 \\
\hline 641114 & 0.6165 & 0.582 & 0.0319 & 0.5792 & 0.0454 & 0.0028 \\
\hline 145621 & 0.6093 & 0.5814 & 0.0328 & 0.5892 & 0.0452 & -0.0078 \\
\hline 315515 & 0.6064 & 0.5474 & 0.0314 & 0.5253 & 0.0405 & 0.0221 \\
\hline 341251 & 0.6023 & 0.5882 & 0.0321 & 0.5543 & 0.0474 & 0.0339 \\
\hline 132524 & 0.5983 & 0.5742 & 0.0271 & 0.523 & 0.0381 & 0.0512 \\
\hline 611154 & 0.5961 & 0.5321 & 0.0343 & 0.5658 & 0.0458 & -0.0337 \\
\hline 611621 & 0.5816 & 0.5301 & 0.0324 & 0.5048 & 0.0489 & 0.0253 \\
\hline 145645 & 0.5814 & 0.5158 & 0.0334 & 0.5222 & 0.0487 & -0.0064 \\
\hline 631315 & 0.5806 & 0.5188 & 0.0334 & 0.4785 & 0.0503 & 0.0403 \\
\hline 443215 & 0.5719 & 0.5798 & 0.0276 & 0.5486 & 0.0376 & 0.0312 \\
\hline 641154 & 0.545 & 0.4952 & 0.0344 & 0.4755 & 0.0489 & 0.0197 \\
\hline 445641 & 0.5364 & 0.4497 & 0.0345 & 0.4331 & 0.0515 & 0.0166 \\
\hline 415651 & 0.5347 & 0.4622 & 0.0353 & 0.4354 & 0.0535 & 0.0268 \\
\hline 145652 & 0.5291 & 0.4513 & 0.0359 & 0.4402 & 0.0519 & 0.0111 \\
\hline 541451 & 0.5194 & 0.502 & 0.0301 & 0.4725 & 0.0454 & 0.0295 \\
\hline 545115 & 0.5171 & 0.5385 & 0.031 & 0.5353 & 0.0435 & 0.0032 \\
\hline 642453 & 0.5104 & 0.4143 & 0.0341 & 0.4048 & 0.0506 & 0.0095 \\
\hline 545353 & 0.5103 & 0.4024 & 0.0341 & 0.3636 & 0.0507 & 0.0388 \\
\hline 415313 & 0.5055 & 0.5463 & 0.0283 & 0.5793 & 0.0378 & -0.033 \\
\hline 633122 & 0.4986 & 0.4906 & 0.0291 & 0.482 & 0.0364 & 0.0086 \\
\hline 645154 & 0.4948 & 0.3667 & 0.0351 & 0.3486 & 0.0521 & 0.0181 \\
\hline 635651 & 0.4884 & 0.3501 & 0.0397 & 0.352 & 0.0587 & -0.0019 \\
\hline 641132 & 0.4794 & 0.4942 & 0.0327 & 0.4441 & 0.046 & 0.0501 \\
\hline 631355 & 0.4479 & 0.4507 & 0.0299 & 0.4277 & 0.0393 & 0.023 \\
\hline 323644 & 0.4377 & 0.4304 & 0.03 & 0.3166 & 0.0384 & 0.1138 \\
\hline 615614 & 0.4344 & 0.4654 & 0.0329 & 0.4935 & 0.0452 & -0.0281 \\
\hline 644631 & 0.416 & 0.4152 & 0.0328 & 0.3867 & 0.0492 & 0.0285 \\
\hline 645441 & 0.4085 & 0.4032 & 0.0323 & 0.3572 & 0.0485 & 0.046 \\
\hline 421455 & 0.4016 & 0.4961 & 0.0283 & 0.4467 & 0.0414 & 0.0494 \\
\hline 613625 & 0.3453 & 0.4022 & 0.0311 & 0.3535 & 0.0473 & 0.0487 \\
\hline 645655 & 0.067 & 0.0544 & 0.0232 & 0.0301 & 0.0331 & 0.0243 \\
\hline
\end{tabular}

Table 2 shows the observed sample mean health state utility with the HK valuations (HK only). The predicted mean valand the posterior mean and standard deviation for population uations for the health states ranged from 0.0301 (pits) to 1 mean utility of the 50 health states in the (HK/UK) together (perfect) for the HK (HK/UK) population. Figure 8 shows 
the predicted mean health state valuations (green line) for the $\mathrm{HK}$ population $(\mathrm{HK} / \mathrm{UK})$ along with the predicted mean health state valuations (red line) for the HK (HK only) population and the observed sample mean health state utility of the 50 health states (blue line). The purple line represents the difference between the two predicted HK valuations. Notice that both valuations are very similar for the majority of the health states. Although both valuations are underestimating the observed valuations, we can see from Figure 8 that the combined HK/UK valuations are below the HK only ones for the majority of health states. This may suggest that a sample of $50 \mathrm{HK}$ health states is still small to produce results that are as good as those obtained with the full HK sample.

\section{Actual vs predicted valuations (50 HK)}

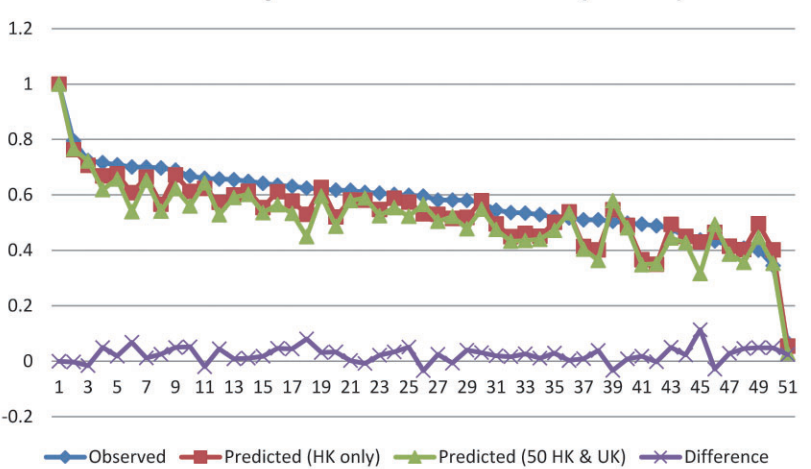

Figure 8. Actual and predicted mean health state valuations for the 50 sampled health states
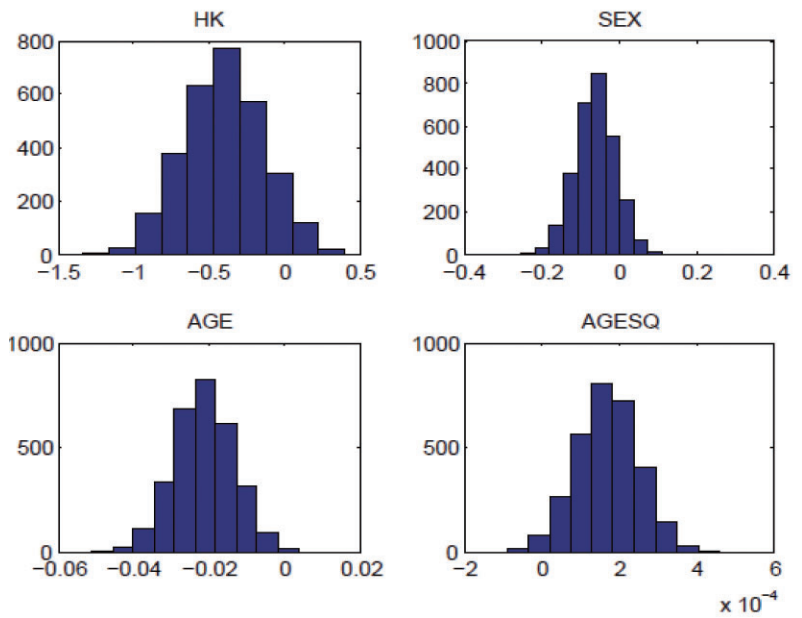

Figure 9. Posterior distribution of the covariates (HK/UK)

Figure 9 shows the posterior distributions of the covariates (HK, Sex, Age and $\mathrm{Age}^{2}$ ) for the (HK/UK) population. As can be seen, these distributions are concentrated away from zero, so these covariates have important effects. In comparison with Figure 3, the sex effect is of opposite sign and about the same magnitude as the main effect for the HK (HK only). Figure 10 shows the mean SG utility values for the pits state for the $(\mathrm{HK} / \mathrm{UK}$. In comparison with Figure 5, we see that both valuations are very similar. Figure 11 shows the posterior distributions of the underlying regression parameters $\gamma$ and $\beta_{1}$ of the HK/UK. In comparison with Figure 7, we see that all of the 6 coefficients in both figures are almost negative, so the fitted parametric relationship for the both analysis satisfy monotonicity.

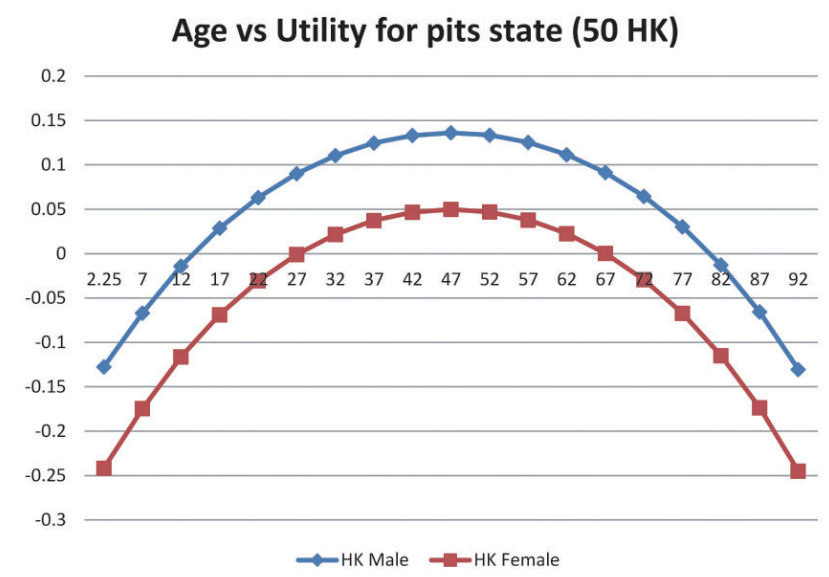

Figure 10. Mean SG utility values by age for pits state: HK/UK

\subsection{HK health states}

Finally, we look at $100 \mathrm{HK}$ health states together with the 249 UK health states. The sample of $100 \mathrm{HK}$ health states was chosen in the same way above. Table 3 shows the observed sample mean health state utility and the posterior mean and standard deviation for population mean utility of the 100 health states in the $(\mathrm{HK} / \mathrm{UK})$ together with the $\mathrm{HK}$ valuations (HK only). The predicted mean valuations for the health states ranged from 0.0478 (pits) to 1 (perfect) for the $\mathrm{HK}(\mathrm{HK} / \mathrm{UK})$ population. Figure 12 shows the predicted mean health state valuations (green line) for the HK population $(\mathrm{HK} / \mathrm{UK})$ along with the predicted mean health state valuations (red line) for the HK (HK only) population and the observed sample mean health state utility of the 100 health states (blue line). The purple line represents the difference between the two HK valuations. Notice that both valuations are very similar for the majority of the health states, although both are underestimating the observed valuations.

Figure 13 shows the posterior distributions of the covariates (HK, Sex, Age and $A g e^{2}$ ). As can be seen, these distributions are concentrated away from zero, so indicates important effects. In comparison with Figure 3, the sex effect is of opposite sign and about the same magnitude as the main effect for the HK (HK only). Figure 14 shows the mean SG utility 
values for the pits state for the (HK/UK). In comparison with Figure 3, we see that both valuations are very similar. Figure 15 show the posterior distributions of the underlying regression parameters $\gamma$ and $\beta_{1}$ of the HK/UK. In comparison with Figure 5, we see that all of the 6 coefficients in both figures are almost negative, so the fitted parametric relationship for the both analysis satisfy monotonicity.

To this end, we compare the two approaches in terms of predicting the values for states that have not been used in the estimation. Note that there are 197 health states in the HK data from which 100 states were used for model fitting above and the remaining 97 states were used for model checking.
Table 4 shows the true sample mean health state utility and the posterior mean and standard deviation for population mean utility of the 97 left out health states in the (HK/UK) together with the HK valuations (HK only). As can be seen, both valuations are very similar for the majority of the health states. The prediction errors are broadly consistent with the predictive standard deviations for the two approaches. The predictive performance for the combined analysis is slightly better though as the variance of the standardised prediction errors is 0.72 for $\mathrm{HK} / \mathrm{UK}$ versus 0.883 for the HK only. Also the root mean square errors (RMSE) of predictions are marginally similar too, with 0.057 for the combined data and 0.074 for the HK only.
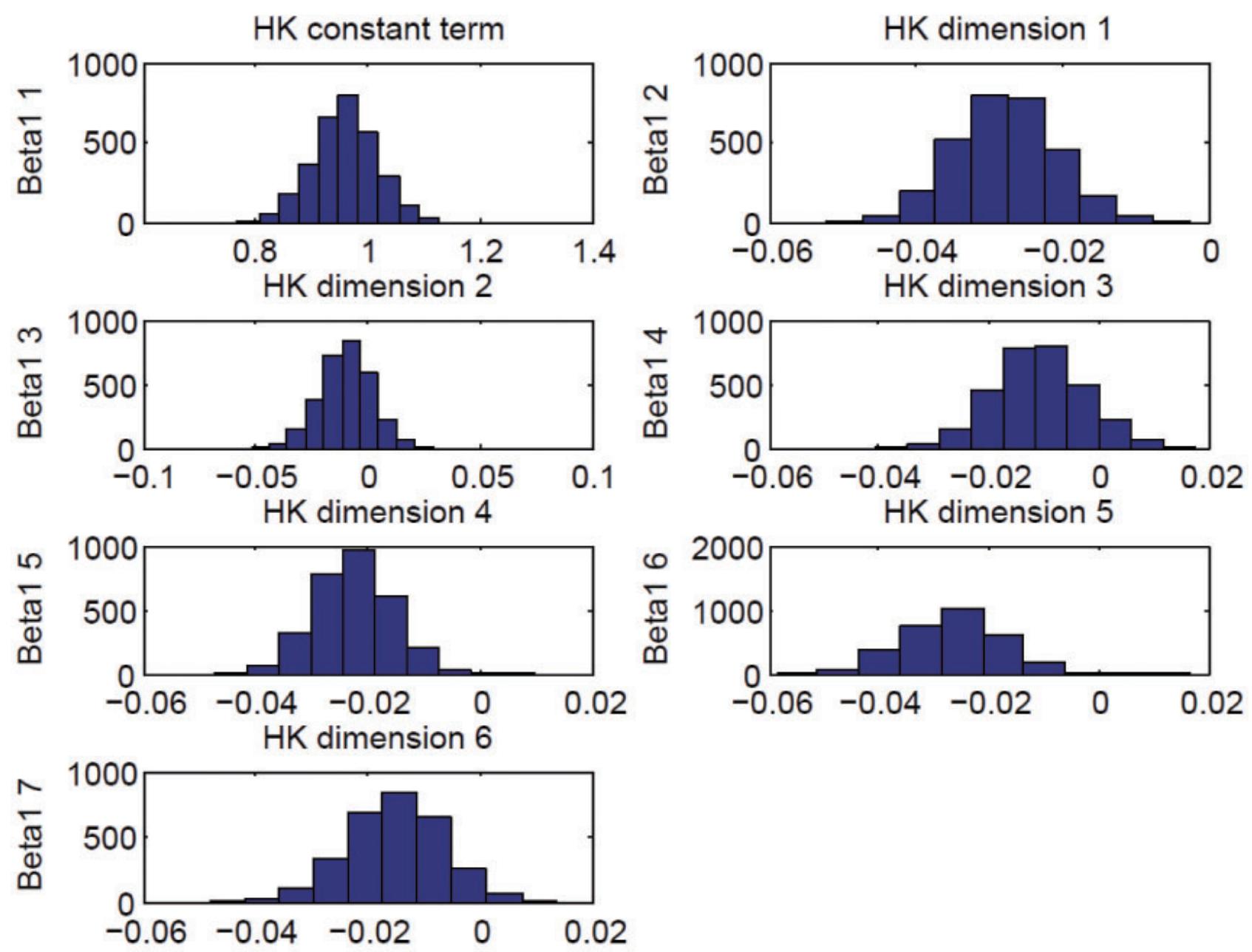

Figure 11. Posterior distribution of the underlying regression parameters $\gamma$ and $\beta$ (HK/UK)

\section{Discussion}

In this article, we have applied a nonparameteric Bayesian method to estimate a utility function applicable across HK and UK to show with a small sample of HK health states, but Published by Sciedu Press also drawing extra information from the UK data, we obtain the same accuracy we would get with the full HK sample. This will be hugely important in countries without the same capacity to run large evaluation exercises. 
Table 3. Posterior estimates for the 100 sampled health states

\begin{tabular}{|c|c|c|c|c|c|c|}
\hline \multirow{2}{*}{$\begin{array}{l}\text { Health } \\
\text { States }\end{array}$} & \multirow{2}{*}{$\begin{array}{l}\text { Observed } \\
\text { mean }\end{array}$} & \multicolumn{2}{|c|}{ HK data ONLY } & \multicolumn{2}{|c|}{100 HK \& UK data } & \multirow[b]{2}{*}{ Difference } \\
\hline & & $\begin{array}{l}\text { Predicted } \\
\text { mean }\end{array}$ & $\begin{array}{l}\text { Predicted } \\
\text { STD }\end{array}$ & $\begin{array}{l}\text { Predicted } \\
\text { mean }\end{array}$ & $\begin{array}{l}\text { Predicted } \\
\text { STD }\end{array}$ & \\
\hline 111111 & 1 & 1 & 0 & 1 & 0 & 0 \\
\hline 113141 & 0.8022 & 0.7541 & 0.0303 & 0.7476 & 0.0383 & 0.0065 \\
\hline 115211 & 0.7951 & 0.7632 & 0.0334 & 0.7547 & 0.0378 & 0.0085 \\
\hline 232111 & 0.7796 & 0.7448 & 0.028 & 0.6869 & 0.0293 & 0.0579 \\
\hline 131331 & 0.7638 & 0.6953 & 0.0306 & 0.6867 & 0.0381 & 0.0086 \\
\hline 113352 & 0.7441 & 0.717 & 0.0275 & 0.6793 & 0.0346 & 0.0377 \\
\hline 133132 & 0.7425 & 0.6949 & 0.0283 & 0.6435 & 0.0297 & 0.0514 \\
\hline 341123 & 0.7389 & 0.6481 & 0.0299 & 0.6261 & 0.034 & 0.022 \\
\hline 115131 & 0.7243 & 0.7068 & 0.0309 & 0.7185 & 0.0389 & -0.0117 \\
\hline 522321 & 0.7164 & 0.6689 & 0.0272 & 0.6068 & 0.031 & 0.0621 \\
\hline 141215 & 0.7089 & 0.6765 & 0.032 & 0.6543 & 0.0441 & 0.0222 \\
\hline 114631 & 0.7057 & 0.6239 & 0.0357 & 0.6043 & 0.0462 & 0.0196 \\
\hline 122425 & 0.704 & 0.6611 & 0.0279 & 0.6408 & 0.0315 & 0.0203 \\
\hline 414522 & 0.7007 & 0.6081 & 0.0314 & 0.5262 & 0.0356 & 0.0819 \\
\hline 135312 & 0.7 & 0.6648 & 0.0281 & 0.6527 & 0.0346 & 0.0121 \\
\hline 244353 & 0.6976 & 0.5668 & 0.0322 & 0.51 & 0.0429 & 0.0568 \\
\hline 122233 & 0.6894 & 0.6726 & 0.0286 & 0.6682 & 0.029 & 0.0044 \\
\hline 142154 & 0.6821 & 0.6313 & 0.0291 & 0.6052 & 0.0342 & 0.0261 \\
\hline 115314 & 0.6788 & 0.6414 & 0.0328 & 0.6635 & 0.0401 & -0.0221 \\
\hline 113615 & 0.6685 & 0.6125 & 0.0346 & 0.5936 & 0.0457 & 0.0189 \\
\hline 241531 & 0.6643 & 0.5999 & 0.0286 & 0.5843 & 0.0331 & 0.0156 \\
\hline 434211 & 0.6601 & 0.6238 & 0.0315 & 0.6151 & 0.0385 & 0.0087 \\
\hline 311654 & 0.6581 & 0.5192 & 0.0355 & 0.4542 & 0.0461 & 0.065 \\
\hline 435335 & 0.6579 & 0.5733 & 0.0304 & 0.5135 & 0.0445 & 0.0598 \\
\hline 135435 & 0.655 & 0.6004 & 0.0303 & 0.5924 & 0.0427 & 0.008 \\
\hline 112153 & 0.6519 & 0.6519 & 0.0306 & 0.6343 & 0.0385 & 0.0176 \\
\hline 235224 & 0.6506 & 0.613 & 0.0285 & 0.5737 & 0.0331 & 0.0393 \\
\hline 111621 & 0.6492 & 0.6136 & 0.0316 & 0.6395 & 0.0302 & -0.0259 \\
\hline 432621 & 0.6423 & 0.5545 & 0.0307 & 0.5239 & 0.0423 & 0.0306 \\
\hline 113634 & 0.64 & 0.5777 & 0.0317 & 0.5539 & 0.0427 & 0.0238 \\
\hline 345411 & 0.6347 & 0.6118 & 0.0315 & 0.5385 & 0.0423 & 0.0733 \\
\hline 343425 & 0.6307 & 0.578 & 0.0297 & 0.526 & 0.0395 & 0.052 \\
\hline 641211 & 0.6294 & 0.5515 & 0.0369 & 0.5146 & 0.0465 & 0.0369 \\
\hline 135155 & 0.6251 & 0.572 & 0.0342 & 0.5294 & 0.0458 & 0.0426 \\
\hline 324155 & 0.6248 & 0.5301 & 0.0349 & 0.4653 & 0.0436 & 0.0648 \\
\hline 615253 & 0.6248 & 0.5072 & 0.0365 & 0.4498 & 0.0507 & 0.0574 \\
\hline 115251 & 0.6223 & 0.626 & 0.0304 & 0.6199 & 0.0396 & 0.0061 \\
\hline 211615 & 0.6206 & 0.6275 & 0.0333 & 0.6125 & 0.0434 & 0.015 \\
\hline 631333 & 0.6175 & 0.521 & 0.0329 & 0.4913 & 0.0427 & 0.0297 \\
\hline 641114 & 0.6165 & 0.582 & 0.0319 & 0.5803 & 0.0428 & 0.0017 \\
\hline 315235 & 0.6161 & 0.5675 & 0.0309 & 0.5769 & 0.0412 & -0.0094 \\
\hline 145621 & 0.6093 & 0.5814 & 0.0328 & 0.5579 & 0.0425 & 0.0235 \\
\hline 412152 & 0.608 & 0.5585 & 0.0267 & 0.5347 & 0.0318 & 0.0238 \\
\hline 315515 & 0.6064 & 0.5474 & 0.0314 & 0.5305 & 0.0367 & 0.0169 \\
\hline 341251 & 0.6023 & 0.5882 & 0.0321 & 0.5583 & 0.0429 & 0.0299 \\
\hline 645415 & 0.6023 & 0.4502 & 0.0381 & 0.4328 & 0.0521 & 0.0174 \\
\hline 341651 & 0.6015 & 0.5161 & 0.0338 & 0.4947 & 0.0452 & 0.0214 \\
\hline 512242 & 0.6013 & 0.5721 & 0.0265 & 0.5561 & 0.0331 & 0.016 \\
\hline 645132 & 0.601 & 0.478 & 0.0358 & 0.4129 & 0.0482 & 0.0651 \\
\hline
\end{tabular}

(Table continued on page 11) 
Table 3. (continued.)

\begin{tabular}{|c|c|c|c|c|c|c|}
\hline \multirow{2}{*}{$\begin{array}{l}\text { Health } \\
\text { States }\end{array}$} & \multirow{2}{*}{$\begin{array}{l}\text { Observed } \\
\text { mean }\end{array}$} & \multicolumn{2}{|c|}{ HK data ONLY } & \multicolumn{2}{|c|}{100 HK \& UK data } & \multirow[b]{2}{*}{ Difference } \\
\hline & & $\begin{array}{l}\text { Predicted } \\
\text { mean }\end{array}$ & $\begin{array}{l}\text { Predicted } \\
\text { STD }\end{array}$ & $\begin{array}{l}\text { Predicted } \\
\text { mean }\end{array}$ & $\begin{array}{l}\text { Predicted } \\
\text { STD }\end{array}$ & \\
\hline 132524 & 0.5983 & 0.5742 & 0.0271 & 0.5518 & 0.033 & 0.0224 \\
\hline 414355 & 0.5976 & 0.5418 & 0.0307 & 0.4868 & 0.0433 & 0.055 \\
\hline 611154 & 0.5961 & 0.5321 & 0.0343 & 0.5403 & 0.0441 & -0.0082 \\
\hline 241135 & 0.5824 & 0.5784 & 0.031 & 0.5635 & 0.0406 & 0.0149 \\
\hline 611621 & 0.5816 & 0.5301 & 0.0324 & 0.5125 & 0.0453 & 0.0176 \\
\hline 145645 & 0.5814 & 0.5158 & 0.0334 & 0.5196 & 0.0468 & -0.0038 \\
\hline 631315 & 0.5806 & 0.5188 & 0.0334 & 0.4854 & 0.0453 & 0.0334 \\
\hline 511633 & 0.5805 & 0.5385 & 0.0302 & 0.4941 & 0.0445 & 0.0444 \\
\hline 115653 & 0.5728 & 0.4944 & 0.0322 & 0.4532 & 0.0406 & 0.0412 \\
\hline 443215 & 0.5719 & 0.5798 & 0.0276 & 0.5523 & 0.0341 & 0.0275 \\
\hline 615315 & 0.5634 & 0.4869 & 0.0354 & 0.4896 & 0.0456 & -0.0027 \\
\hline 614135 & 0.5587 & 0.4997 & 0.0355 & 0.4938 & 0.0446 & 0.0059 \\
\hline 441331 & 0.557 & 0.5554 & 0.0294 & 0.5448 & 0.0363 & 0.0106 \\
\hline 144341 & 0.5565 & 0.5665 & 0.0284 & 0.5787 & 0.0304 & -0.0122 \\
\hline 641154 & 0.545 & 0.4952 & 0.0344 & 0.4732 & 0.0478 & 0.022 \\
\hline 445641 & 0.5364 & 0.4497 & 0.0345 & 0.415 & 0.0486 & 0.0347 \\
\hline 415651 & 0.5347 & 0.4622 & 0.0353 & 0.4276 & 0.0506 & 0.0346 \\
\hline 145652 & 0.5291 & 0.4513 & 0.0359 & 0.4371 & 0.0486 & 0.0142 \\
\hline 611652 & 0.5207 & 0.4095 & 0.0361 & 0.4 & 0.0478 & 0.0095 \\
\hline 541451 & 0.5194 & 0.502 & 0.0301 & 0.4735 & 0.0416 & 0.0285 \\
\hline 545115 & 0.5171 & 0.5385 & 0.031 & 0.5262 & 0.0418 & 0.0123 \\
\hline 622513 & 0.5108 & 0.5061 & 0.0274 & 0.4517 & 0.0372 & 0.0544 \\
\hline 642453 & 0.5104 & 0.4143 & 0.0341 & 0.4092 & 0.0469 & 0.0051 \\
\hline 545353 & 0.5103 & 0.4024 & 0.0341 & 0.3521 & 0.0482 & 0.0503 \\
\hline 534113 & 0.5076 & 0.5044 & 0.0293 & 0.5161 & 0.0358 & -0.0117 \\
\hline 415313 & 0.5055 & 0.5463 & 0.0283 & 0.5838 & 0.0362 & -0.0375 \\
\hline 143654 & 0.5028 & 0.4905 & 0.0322 & 0.4641 & 0.0442 & 0.0264 \\
\hline 344633 & 0.5002 & 0.468 & 0.0316 & 0.4478 & 0.0416 & 0.0202 \\
\hline 633122 & 0.4986 & 0.4906 & 0.0291 & 0.4759 & 0.0331 & 0.0147 \\
\hline 645154 & 0.4948 & 0.3667 & 0.0351 & 0.3453 & 0.0488 & 0.0214 \\
\hline 635651 & 0.4884 & 0.3501 & 0.0397 & 0.3336 & 0.0549 & 0.0165 \\
\hline 441615 & 0.4883 & 0.4979 & 0.0316 & 0.4459 & 0.0446 & 0.052 \\
\hline 641654 & 0.4842 & 0.4086 & 0.0356 & 0.4013 & 0.0503 & 0.0073 \\
\hline 641132 & 0.4794 & 0.4942 & 0.0327 & 0.4564 & 0.042 & 0.0378 \\
\hline 345355 & 0.4751 & 0.4782 & 0.0302 & 0.4324 & 0.0445 & 0.0458 \\
\hline 415655 & 0.4739 & 0.3966 & 0.0361 & 0.3472 & 0.053 & 0.0494 \\
\hline 611645 & 0.4649 & 0.4465 & 0.032 & 0.4091 & 0.048 & 0.0374 \\
\hline 623155 & 0.4501 & 0.4516 & 0.0341 & 0.4273 & 0.0459 & 0.0243 \\
\hline 642612 & 0.4496 & 0.4718 & 0.0295 & 0.4078 & 0.0384 & 0.064 \\
\hline 631355 & 0.4479 & 0.4507 & 0.0299 & 0.4239 & 0.0396 & 0.0268 \\
\hline 615451 & 0.4431 & 0.4229 & 0.0339 & 0.4014 & 0.0476 & 0.0215 \\
\hline 443652 & 0.4431 & 0.3972 & 0.0322 & 0.3873 & 0.0441 & 0.0099 \\
\hline 323644 & 0.4377 & 0.4304 & 0.03 & 0.3614 & 0.0367 & 0.069 \\
\hline 615614 & 0.4344 & 0.4654 & 0.0329 & 0.4904 & 0.0433 & -0.025 \\
\hline 644631 & 0.416 & 0.4152 & 0.0328 & 0.3821 & 0.0473 & 0.0331 \\
\hline 615412 & 0.4129 & 0.4956 & 0.0301 & 0.4791 & 0.0395 & 0.0165 \\
\hline 645441 & 0.4085 & 0.4032 & 0.0323 & 0.3545 & 0.0466 & 0.0487 \\
\hline 421455 & 0.4016 & 0.4961 & 0.0283 & 0.4708 & 0.0379 & 0.0253 \\
\hline 613625 & 0.3453 & 0.4022 & 0.0311 & 0.368 & 0.0442 & 0.0342 \\
\hline 445145 & 0.3405 & 0.4656 & 0.0291 & 0.4369 & 0.0395 & 0.0287 \\
\hline 633535 & 0.3343 & 0.3641 & 0.0309 & 0.3239 & 0.0451 & 0.0402 \\
\hline 645655 & 0.067 & 0.0544 & 0.0232 & 0.0478 & 0.042 & 0.0066 \\
\hline
\end{tabular}


Actual vs predicted valuations (100 HK)

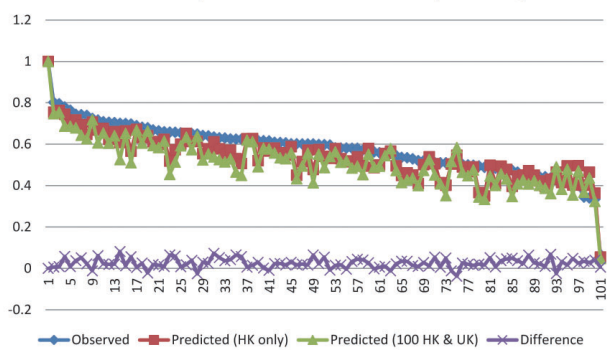

Figure 12. Actual and predicted mean health state valuations for the 100 sampled health states
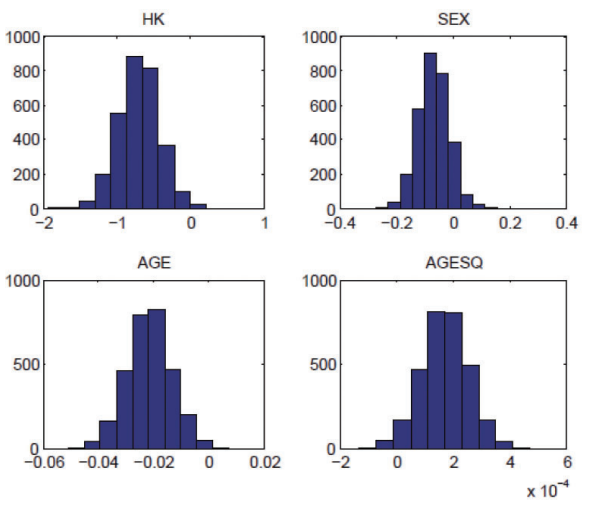

Figure 13. Posterior distribution of the covariates (HK/UK)
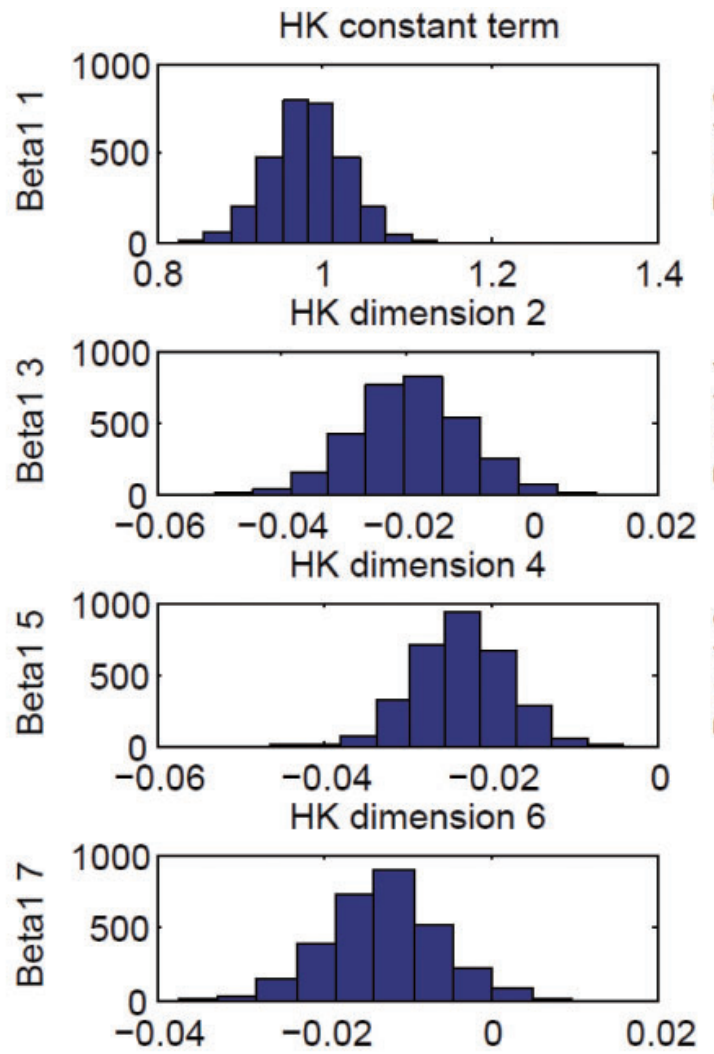

Age vs Utility for pits state (100 HK)

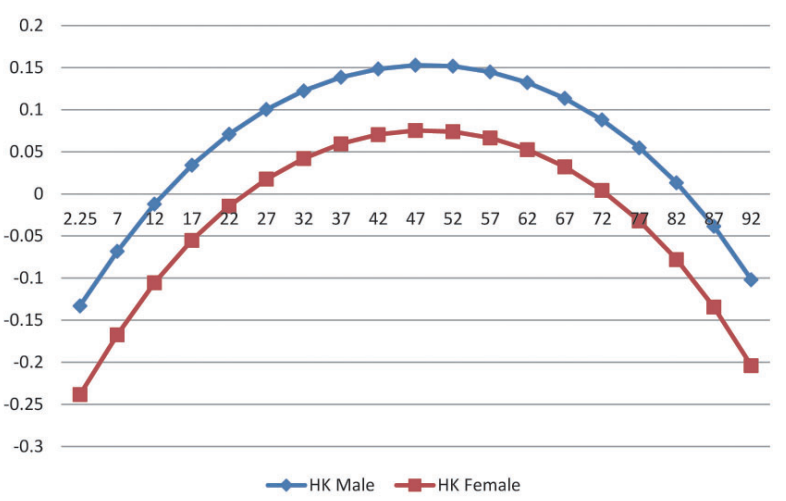

Figure 14. Posterior distribution of the covariates (HK/UK)

The work presented in this paper demonstrates that with 25 , 50 and 100 states, the HK analysis gets the broad features as the full analysis with all states as far as predicted mean valuations, covariates and interactions are concerned. However, in terms of the dimension-specific parameters $\beta_{1}$, there is more uncertainty and possibility of larger effects with 25 and/or 50 health states, and with 100 states we get effects of about the right magnitude and mostly negative. This implies that reducing the numbers of states to 25 and/or 50 runs the risk of misestimating the dimension-specific effects.
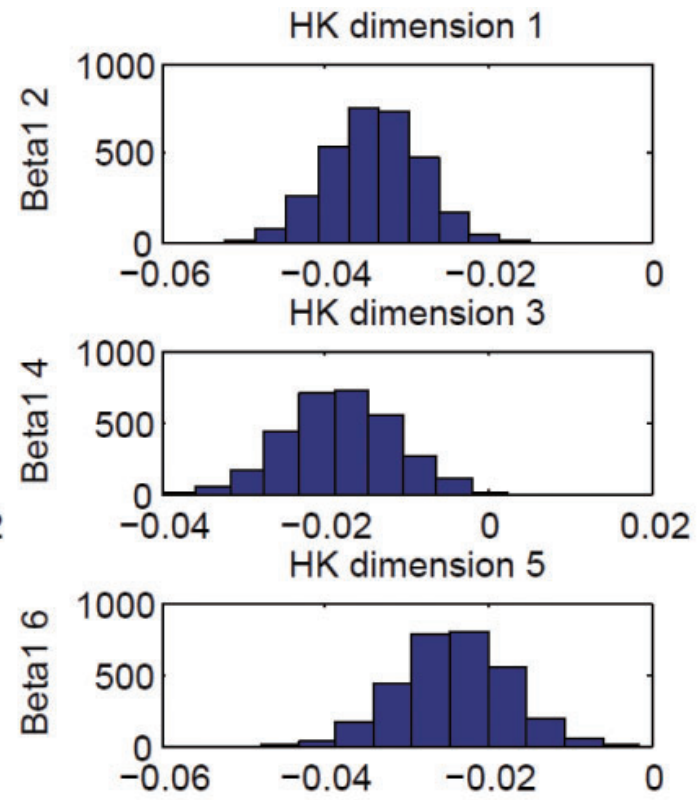

Figure 15. Posterior distribution of the underlying regression parameters $\gamma$ and $\beta$ (HK/UK) 
Table 4. Predictions for 97 left out health states

\begin{tabular}{|c|c|c|c|c|c|c|}
\hline \multirow{2}{*}{$\begin{array}{l}\text { Health } \\
\text { States }\end{array}$} & \multirow{2}{*}{$\begin{array}{l}\text { Observed } \\
\text { mean }\end{array}$} & \multicolumn{2}{|c|}{ HK data ONLY } & \multicolumn{2}{|c|}{100 HK \& UK data } & \multirow[b]{2}{*}{ Difference } \\
\hline & & $\begin{array}{l}\text { Predicted } \\
\text { mean }\end{array}$ & $\begin{array}{l}\text { Predicted } \\
\text { STD }\end{array}$ & $\begin{array}{l}\text { Predicted } \\
\text { mean }\end{array}$ & $\begin{array}{l}\text { Predicted } \\
\text { STD }\end{array}$ & \\
\hline 111645 & 0.5055 & 0.6273 & 0.0715 & 0.5573 & 0.074 & 0.07 \\
\hline 112455 & 0.6777 & 0.6265 & 0.0713 & 0.5367 & 0.0703 & 0.0898 \\
\hline 112613 & 0.7305 & 0.7045 & 0.0638 & 0.7144 & 0.0673 & -0.0099 \\
\hline 112651 & 0.6288 & 0.6758 & 0.0686 & 0.6173 & 0.0698 & 0.0585 \\
\hline 113411 & 0.7324 & 0.7979 & 0.0637 & 0.7084 & 0.0513 & 0.0895 \\
\hline 115355 & 0.5346 & 0.5684 & 0.0753 & 0.4918 & 0.0736 & 0.0766 \\
\hline 115432 & 0.6201 & 0.6126 & 0.0714 & 0.5925 & 0.0766 & 0.0201 \\
\hline 121212 & 0.8253 & 0.8356 & 0.0631 & 0.7905 & 0.0533 & 0.0451 \\
\hline 124125 & 0.612 & 0.6983 & 0.0658 & 0.6893 & 0.0612 & 0.009 \\
\hline 125143 & 0.6505 & 0.5835 & 0.0748 & 0.5365 & 0.0751 & 0.047 \\
\hline 125625 & 0.5478 & 0.6113 & 0.0664 & 0.5835 & 0.0714 & 0.0278 \\
\hline 131151 & 0.7621 & 0.6964 & 0.073 & 0.6924 & 0.0799 & 0.004 \\
\hline 131542 & 0.7067 & 0.6521 & 0.0579 & 0.5937 & 0.0483 & 0.0584 \\
\hline 131555 & 0.5327 & 0.5549 & 0.0737 & 0.496 & 0.0709 & 0.0589 \\
\hline 135633 & 0.5085 & 0.5565 & 0.068 & 0.5279 & 0.0739 & 0.0286 \\
\hline 142113 & 0.6585 & 0.716 & 0.0694 & 0.6392 & 0.0703 & 0.0768 \\
\hline 142335 & 0.6654 & 0.6343 & 0.0611 & 0.5983 & 0.0651 & 0.036 \\
\hline 143641 & 0.5733 & 0.56 & 0.0662 & 0.5387 & 0.0673 & 0.0213 \\
\hline 144455 & 0.5676 & 0.5704 & 0.0659 & 0.5339 & 0.0717 & 0.0365 \\
\hline 144613 & 0.6916 & 0.6428 & 0.0677 & 0.6306 & 0.0708 & 0.0122 \\
\hline 145515 & 0.5903 & 0.6118 & 0.0738 & 0.6116 & 0.0798 & 0.0002 \\
\hline 211111 & 0.8584 & 0.9575 & 0.0447 & 0.9036 & 0.0453 & 0.0539 \\
\hline 211251 & 0.6738 & 0.685 & 0.0714 & 0.6365 & 0.0751 & 0.0485 \\
\hline 211633 & 0.7051 & 0.6666 & 0.0578 & 0.6791 & 0.0593 & -0.0125 \\
\hline 212145 & 0.6188 & 0.618 & 0.0711 & 0.6037 & 0.0603 & 0.0143 \\
\hline 213323 & 0.6571 & 0.6867 & 0.0612 & 0.6875 & 0.0464 & -0.0008 \\
\hline 214435 & 0.5943 & 0.535 & 0.0695 & 0.4488 & 0.0653 & 0.0862 \\
\hline 221452 & 0.6627 & 0.6167 & 0.0685 & 0.523 & 0.0644 & 0.0937 \\
\hline 224612 & 0.6385 & 0.6335 & 0.0672 & 0.5417 & 0.0554 & 0.0918 \\
\hline 243433 & 0.5053 & 0.4704 & 0.0706 & 0.4919 & 0.0625 & -0.0215 \\
\hline 243615 & 0.5913 & 0.5428 & 0.0684 & 0.5502 & 0.0721 & -0.0074 \\
\hline 312332 & 0.701 & 0.6856 & 0.0614 & 0.6578 & 0.0497 & 0.0278 \\
\hline 315123 & 0.5582 & 0.6687 & 0.0627 & 0.7099 & 0.0648 & -0.0412 \\
\hline 315341 & 0.6486 & 0.6633 & 0.0611 & 0.6654 & 0.0635 & -0.0021 \\
\hline 321122 & 0.7987 & 0.7816 & 0.0547 & 0.7578 & 0.0428 & 0.0238 \\
\hline 325433 & 0.5685 & 0.5467 & 0.0678 & 0.5302 & 0.0645 & 0.0165 \\
\hline 331115 & 0.6584 & 0.6751 & 0.069 & 0.6607 & 0.0704 & 0.0144 \\
\hline 332411 & 0.6152 & 0.6261 & 0.0666 & 0.6045 & 0.0559 & 0.0216 \\
\hline 333135 & 0.631 & 0.5055 & 0.0731 & 0.4745 & 0.0634 & 0.031 \\
\hline 333455 & 0.6131 & 0.4976 & 0.0662 & 0.4373 & 0.0643 & 0.0603 \\
\hline 334251 & 0.5031 & 0.535 & 0.0694 & 0.504 & 0.0684 & 0.031 \\
\hline 341414 & 0.7513 & 0.6491 & 0.0593 & 0.6625 & 0.0621 & -0.0134 \\
\hline 341634 & 0.5209 & 0.3929 & 0.0791 & 0.379 & 0.0693 & 0.0139 \\
\hline 342613 & 0.6672 & 0.5917 & 0.0611 & 0.5751 & 0.0628 & 0.0166 \\
\hline 345153 & 0.4966 & 0.5408 & 0.0677 & 0.4768 & 0.0713 & 0.064 \\
\hline 345535 & 0.6564 & 0.5834 & 0.0579 & 0.5936 & 0.0606 & -0.0102 \\
\hline 345553 & 0.4538 & 0.4327 & 0.0656 & 0.4238 & 0.0687 & 0.0089 \\
\hline 411612 & 0.6595 & 0.6199 & 0.0658 & 0.601 & 0.0699 & 0.0189 \\
\hline 413212 & 0.6879 & 0.6641 & 0.0748 & 0.5846 & 0.0716 & 0.0795 \\
\hline
\end{tabular}


Table 4. (continued.)

\begin{tabular}{|c|c|c|c|c|c|c|}
\hline \multirow{2}{*}{$\begin{array}{l}\text { Health } \\
\text { States }\end{array}$} & \multirow{2}{*}{$\begin{array}{l}\text { Observed } \\
\text { mean }\end{array}$} & \multicolumn{2}{|c|}{ HK data ONLY } & \multicolumn{2}{|c|}{100 HK \& UK data } & \multirow[b]{2}{*}{ Difference } \\
\hline & & $\begin{array}{l}\text { Predicted } \\
\text { mean }\end{array}$ & $\begin{array}{l}\text { Predicted } \\
\text { STD }\end{array}$ & $\begin{array}{l}\text { Predicted } \\
\text { mean }\end{array}$ & $\begin{array}{l}\text { Predicted } \\
\text { STD }\end{array}$ & \\
\hline 415115 & 0.6264 & 0.6169 & 0.0686 & 0.618 & 0.0714 & -0.0011 \\
\hline 415453 & 0.5826 & 0.5256 & 0.0642 & 0.546 & 0.0675 & -0.0204 \\
\hline 421314 & 0.6607 & 0.6322 & 0.0667 & 0.583 & 0.0554 & 0.0492 \\
\hline 421641 & 0.6118 & 0.6027 & 0.0613 & 0.5944 & 0.0631 & 0.0083 \\
\hline 423435 & 0.6172 & 0.5866 & 0.0591 & 0.5547 & 0.0592 & 0.0319 \\
\hline 423615 & 0.6373 & 0.5683 & 0.0622 & 0.5417 & 0.064 & 0.0266 \\
\hline 425131 & 0.5312 & 0.5509 & 0.0778 & 0.4981 & 0.074 & 0.0528 \\
\hline 431443 & 0.5838 & 0.5202 & 0.0638 & 0.5026 & 0.0543 & 0.0176 \\
\hline 441255 & 0.5133 & 0.5395 & 0.0671 & 0.5056 & 0.0675 & 0.0339 \\
\hline 442655 & 0.353 & 0.3039 & 0.0777 & 0.2824 & 0.0777 & 0.0215 \\
\hline 444611 & 0.6854 & 0.5756 & 0.064 & 0.5313 & 0.0688 & 0.0443 \\
\hline 445233 & 0.4914 & 0.4717 & 0.0693 & 0.4309 & 0.0677 & 0.0408 \\
\hline 445615 & 0.4775 & 0.4955 & 0.0724 & 0.4659 & 0.0744 & 0.0296 \\
\hline 511114 & 0.6239 & 0.672 & 0.0792 & 0.6098 & 0.0583 & 0.0622 \\
\hline 511435 & 0.6804 & 0.5411 & 0.0684 & 0.5601 & 0.0677 & -0.019 \\
\hline 511615 & 0.5991 & 0.5136 & 0.0712 & 0.4842 & 0.077 & 0.0294 \\
\hline 513654 & 0.4584 & 0.4403 & 0.0679 & 0.4286 & 0.0694 & 0.0117 \\
\hline 515155 & 0.6677 & 0.5897 & 0.0619 & 0.5842 & 0.0645 & 0.0055 \\
\hline 523551 & 0.6141 & 0.5495 & 0.0616 & 0.5384 & 0.058 & 0.0111 \\
\hline 531635 & 0.5015 & 0.4516 & 0.0656 & 0.3993 & 0.0571 & 0.0523 \\
\hline 533415 & 0.5342 & 0.5309 & 0.0622 & 0.4858 & 0.0663 & 0.0451 \\
\hline 543533 & 0.4771 & 0.4381 & 0.0628 & 0.4964 & 0.0581 & -0.0583 \\
\hline 545151 & 0.5136 & 0.4451 & 0.077 & 0.3824 & 0.0806 & 0.0627 \\
\hline 545422 & 0.6088 & 0.4837 & 0.061 & 0.4749 & 0.0497 & 0.0088 \\
\hline 611221 & 0.681 & 0.74 & 0.0618 & 0.6524 & 0.0593 & 0.0876 \\
\hline 611432 & 0.4712 & 0.4963 & 0.071 & 0.4485 & 0.0714 & 0.0478 \\
\hline 611454 & 0.3346 & 0.4306 & 0.0704 & 0.4209 & 0.0749 & 0.0097 \\
\hline 612415 & 0.4566 & 0.4789 & 0.0726 & 0.4221 & 0.0782 & 0.0568 \\
\hline 614434 & 0.4449 & 0.4812 & 0.0645 & 0.4868 & 0.056 & -0.0056 \\
\hline 615455 & 0.4993 & 0.4006 & 0.0706 & 0.4056 & 0.0749 & -0.005 \\
\hline 615631 & 0.5056 & 0.5136 & 0.0683 & 0.4403 & 0.0734 & 0.0733 \\
\hline 615653 & 0.381 & 0.3951 & 0.073 & 0.4135 & 0.0775 & -0.0184 \\
\hline 621135 & 0.4934 & 0.5357 & 0.0731 & 0.5399 & 0.074 & -0.0042 \\
\hline 623353 & 0.4256 & 0.4701 & 0.0687 & 0.4 & 0.0662 & 0.0701 \\
\hline 624431 & 0.5694 & 0.5654 & 0.0653 & 0.4795 & 0.0604 & 0.0859 \\
\hline 624633 & 0.3082 & 0.2823 & 0.0791 & 0.26 & 0.0739 & 0.0223 \\
\hline 625141 & 0.5605 & 0.5282 & 0.0704 & 0.4287 & 0.0611 & 0.0995 \\
\hline 631632 & 0.4974 & 0.4633 & 0.0702 & 0.4186 & 0.0709 & 0.0447 \\
\hline 632615 & 0.5484 & 0.4196 & 0.0681 & 0.3918 & 0.073 & 0.0278 \\
\hline 633653 & 0.4335 & 0.371 & 0.0683 & 0.4049 & 0.069 & -0.0339 \\
\hline 635611 & 0.4001 & 0.4323 & 0.0791 & 0.3649 & 0.0815 & 0.0674 \\
\hline 642151 & 0.5356 & 0.4967 & 0.0719 & 0.4531 & 0.0774 & 0.0436 \\
\hline 642313 & 0.5499 & 0.5602 & 0.0624 & 0.5992 & 0.0655 & -0.039 \\
\hline 642651 & 0.3731 & 0.3614 & 0.0716 & 0.332 & 0.0788 & 0.0294 \\
\hline 643125 & 0.5007 & 0.5278 & 0.0661 & 0.5429 & 0.0681 & -0.0151 \\
\hline 643143 & 0.463 & 0.4929 & 0.066 & 0.4857 & 0.0676 & 0.0072 \\
\hline 644614 & 0.4387 & 0.4697 & 0.0687 & 0.4594 & 0.0702 & 0.0103 \\
\hline 645235 & 0.3724 & 0.3304 & 0.0729 & 0.3397 & 0.0765 & -0.0093 \\
\hline
\end{tabular}


A key point worth mentioning is that the choice of HK samples does not have a big effect on how well we can estimate the parameters. Although the results presented here are based on health states selected randomly in terms of UK posterior mean utilities, we have obtained (results not shown) similar results when 1) health states are chosen to be well spread over the space of states and 2) health states selected randomly in terms of UK posterior standard deviation values.

The nonparametric model brings two potential advantages. Firstly, where there is sufficient data in one country to estimate a model but few data on another, the pooled analysis produces better estimation of the second country's population utility function than analyzing its data separately. Understanding this will be hugely important in terms of reducing the need for large surveys being undertaken using expensive and often time consuming face to face interviews with techniques such as SG and TTO in every country. Secondly, a Bayesian approach offers the potential for using the results in one country to inform the design in another country by using the results in one country as informative priors. We believe this type of analysis may also allow us to produce better estimation to the second country's population utility function than analyzing its data separately. Work in progress on demonstrating this idea.

The model is applicable to other generic health state descriptive systems such as EQ-5D and HUI-II, as well as to more specialised, disease-specific systems. Work is in progress on application to EQ-5D system. Matlab code for implementing the nonparametric model is available on request.

\section{ETHICAL APPROVAL}

This article does not contain any studies with human participants or animals performed by the author.

\section{CONFLiCTS OF INTEREST Disclosure}

The author declares that he has no conflict of interest.

\section{REFERENCES}

[1] Brazier JE, Ratcliffe J, Tsuchiya A, et al. Measuring and valuing health for economic evaluation. Oxford: Oxford University Press. $2007 \mathrm{a}$.

[2] Brooks R. EuroQol: the current state of play. Health policy. 1996; 37: 53(72). http://dx.doi.org/10.1016/0168-8510(96) 008 22-6

[3] Torrance GW, Feeny DH, Furlong WJ, et al. Multi-attribute utility function for a comprehensive health status classification system: Health Utilities Index Mark 2. Medical Care. 1996; 34(7); 702-22. http://dx.doi.org/10.1097/00005650-199607000-00004

[4] Feeny DH, Furlong WJ, Torrance GW, et al. Multi-attribute and single-attribute utility function for the Health Utility Index Mark 3 system. Medical care. 2002; 40(20): 113(128).

[5] Hawthorne G, Richardson G, Atherton_Day N. A comparison of the Assessment of Quality of Life (AQoL) with four other generic utility instruments. Annals of Medicine. 2001; 33: 358-70. http: //dx.doi.org/10.3109/07853890109002090

[6] Brazier JE, Roberts J, Deverill M. The estimation of a preferencebased measure of health from the SF-36. Journal of Health Economics. 2002; 21: 271(292). http://dx.doi .org/10.1016/S01 67-6296 (01) 00130-8

[7] Revicki DA, Leidy NK, Brennan-Diemer F, et al. Integrating patients' preferences into health outcomes assessment: the multiattribute asthma symptom utility index. Chest. 1998; 114(4): 998-1007. PMid: 9792568. http://dx.doi.org/10.1378/chest.114.4.998

[8] Brazier JE, Czoski-Murray C, Roberts J, et al. Estimation of a preference-based index from a condition specific measure: the King's Health Questionnaire. Medical Decision Making. 2008; (1): 113-26.

[9] Yang Y, Brazier JE, Tsuchiya A, et al. Estimating a Preference-Based Index from the Overactive Bladder Questionnaire. Value in Health. 2009; 12: 159-66. PMid: 18647258. http://dx.doi.org/10.11 $11 / j .1524-4733.2008 .00413 . x$

Published by Sciedu Press
[10] Yang Y, Brazier JE, Tsuchiya A, et al. Estimating a PreferenceBased Index for a 5-Dimensional Health State Classification for Asthma Derived from the Asthma Quality of Life Questionnaire. Medical Decision Making. 2011; 31: 281-91. PMid: 20924045. http://dx.doi.org/10.1177/0272989X10379646

[11] Drummond MF, Sculpher M, O'Brien B, et al. Methods for the economic evaluation of health care programmes. Oxford: Oxford Medical Publications. 2005.

[12] Cruz LC, Camey SA, Hoffman JF, et al. Estimating the SF-6D value set for a Southern Brazilian Population. Value in Health. 2011; 14(5): S108-14. PMid: 21839880. http://dx.doi.org/10.1016/j.j val.2011.05.012

[13] Ferreira LN, Ferreira PL, Brazier J, et al. A Portugese value set for the SF-6D. Value in Health. 2010; 13(5): 624-30. PMid: 20230545. http://dx.doi.org/10.1111/j.1524-4733.2010.00701.x

[14] Brazier JE, Fukuhara S, Roberts J, et al. Estimating a preferencebased index from the Japanese SF-36. Journal of Clinical Epidemiology. 2009; 62(12): 1323-31. PMid: 19615856. http://dx.doi.o $\mathrm{rg} / 10.1016 / \mathrm{j} \cdot \mathrm{jclinepi} .2009 .01 .022$

[15] McGhee SM, Brazier J, Lam CLK, et al. Quality adjusted life years: Population specific measurement of the quality component. Hong Kong Med J. 2011; 17(Suppl 6): S17-21.

[16] Norman R, Viney R, Brazier J, et al. Valuing SF-6D health states using a discrete choice experiment. Med Decis Making. 2013; 34(6): 773-86. PMid: 24025661. http://dx. doi .org/10.1177/02729 89X13503499

[17] Badia X, Roset M, Herdman M. et al. A comparison of United Kingdom and Spanish general population time trade-off values for EQ-5D health states. Medical Decision Making. 2001; 20: 7-16. http://dx.doi.org/10.1177/0272989X0102100102

[18] Johnson JA, Luo N, Shaw JW, et al. (2005). Valuations of EQ-5D Health States; Are the United States and United Kingdom Different. Medical Care. 2005; 43: 221-8. http://dx.doi .org/10.1097/0 0005650-200503000-00004 
[19] Tsuchiya A, Ikeda S, Ikegami N, et al. Estimating an EQ-5D population value set: the case of Japan. Health Econ. 2002; 11: 341-53. PMid: 12007165. http://dx.doi.org/10.1002/hec.673

[20] Ferreira LN, Ferreira PL, Rowen D, et al. Do Portuguese and UK health state values differ across valuation methods? Quality of Life Research. 2011; 20(4): 609-19. PMid: 21061071. http: //dx.doi.org/10.1007/s11136-010-9785-3

[21] Kharroubi SA, O'Hagan A, Brazier JE. A comparison of United States and United Kingdom EQ-5D health state valuations using a nonparametric Bayesian method. Statistics in Medicine. 2010; 29: 1622-34. http://dx.doi.org/10.1002/sim. 3874

[22] Kharroubi SA, Brazier J, McGhee S. A comparison of Hong Kong and United Kingdom SF-6D health states valuations using a nonparametric Bayesian method. Value in Health. 2014; 17(4): 397-405. PMid: 24969000. http://dx.doi.org/10.1016/j.jval. 2014 .02 .011
[23] Kharroubi SA. A comparison of Japan and United Kingdom SF-6D health states valuations using a nonparametric Bayesian method. Applied Health Economics Policy. 2015; 13: 409-20. PMid: 25896874. http://dx.doi.org/10.1007/s40258-015-0171-8

[24] Kharroubi SA, O'Hagan A, Brazier JE. Estimating Utilities from individual health state preference data: a nonparametric Bayesian approach. Applied Statistics. 2005; 54: 879-95. http://dx.doi.o $\mathrm{rg} / 10.1111 / \mathrm{j} .1467-9876.2005 .00511 . \mathrm{x}$

[25] Ware JE, Sherbourne CD. The MOS 36-item Short-Form Health Survey (SF-36): Conceptual framework and item selection. Medical Care. 1992; 30: 473-83. http://dx.doi.org/10.1097/0000565 0-199206000-00002

[26] Furlong W, Feeny D, Torrance GW, et al. Guide to design and development of health state utility instrumentation. Centre for Health Economics and Policy Analysis Paper 90-9, McMaster University, Hamilton, Ont. 1990. 